\title{
Electrospray Ionization Mass Spectrometry Fingerprinting of Extracts of the Leaves of Arrabidaea chica
}

\author{
Adriana L. Schiozer, ${ }^{a}$ Elaine C. Cabral, ${ }^{b, c}$ Luiz A. F. de Godoy, ${ }^{d}$ Francisco C. M. Chaves, ${ }^{e}$ \\ Ronei J. Poppi, ${ }^{a}$ José M. Riveros, ${ }^{c}$ Marcos N. Eberlin ${ }^{b}$ and Lauro E. S. Barata ${ }^{*, a}$ \\ ${ }^{a}$ Laboratory of Natural Products and ${ }^{b}$ ThoMSon Mass Spectrometry Laboratory, Institute of Chemistry, \\ University of Campinas (Unicamp), CP 6154, 13083-970 Campinas-SP, Brazil \\ 'Institute of Chemistry, University of São Paulo (USP), CP 26077, 05513-970 São Paulo-SP, Brazil \\ ${ }^{d}$ Chemometric Laboratory in Analytical Chemistry, Institute of Chemistry, University of Campinas \\ (Unicamp), CP 6154, 13083-970 Campinas-SP, Brazil
}

${ }^{e}$ Centro de Pesquisa Agroflorestal da Amazônia Ocidental, Embrapa Amazônia Ocidental, CP 319, 69010-970 Manaus-AM, Brazil

\begin{abstract}
Arrabidaea chica (crajiru) é uma importante planta da Amazônia. Seus extratos são usados como pigmento, agentes antimicrobianos e adstringentes. Três variedades diferentes desta espécie são cultivadas na região Amazônica. Neste trabalho, infusões diretas de extratos de $A$. chica destas três variedade foram analisadas por impressão digital via espectrometria de massas com ionização por eletrospray (ESI(+)-MS). Dados derivados destes espectros foram classificados utilizando um método de análise multivariada (PLS-DA, análise discriminante com calibração multivariada por mínimos quadrados parciais). O método direto aqui apresentado baseia-se na extração de folhas secas e em pó com uma solução de metanol/água acidificada sem manipulação adicional da amostra. A solução sobrenadante foi analisada através de infusão direta por ESI(+)-MS, o que resultou em perfis de composição para cada variedade. 3-Desoxiantocianidinas são importantes substâncias presentes na $A$. chica, seus íons foram usados como marcadores no tratamento de dados utilizando PLS-DA, o que possibilitou a separação das três variedades. Impressão digital por ESI(+)-MS funciona como um método simples e rápido para diferenciação de variedades de $A$. chica.
\end{abstract}

Arrabidaea chica (crajiru) is an important Amazonian plant. Its extracts are used as red pigments, antimicrobial agents and astringents. Three different varieties of this species are cultivated in the Amazon region. In this work, direct infusions of $A$. chica extracts from these three varieties were analyzed via electrospray ionization mass spectrometry (ESI(+)-MS) fingerprinting. Derived data from the spectra were classified by using a multivariate method (PLS-DA, partial least squares-discriminant analysis). The direct method that is herein presented relies on extraction of dry, powdered leaves with acidified methanol/water solution with no further sample preparation. The resulting supernatants were analyzed by direct infusion ESI(+)-MS, which provides characteristic fingerprints of the sample composition. 3-Deoxyanthocyanidins are important substances in A. chica, their ions were used as markers in the PLS-DA data treatment. PLS-DA was able to differentiate the three varieties. ESI(+)-MS fingerprinting works as a simple and fast method to differentiate varieties of A. chica.

Keywords: Arrabidaea chica, crajiru, ESI-MS fingerprinting, 3-deoxyanthocyanidinins, multivariate analysis

\section{Introduction}

Arrabidaea chica (Humb. \& Bonpl.) Verlot, Bignoniaceae, popularly known as crajiru, pariri, chica and puca panga,

*e-mail: lbarata@iqm.unicamp.br among others, is distributed from Mexico to Argentina. ${ }^{1}$ It is widely cultivated in the Amazon region where its leaves are traditionally used as astringents, feminine genital disinfectants, in the treatment of inflammation, skin disease and wound-healing, intestinal cramps, bloody dysentery, leucorrhoea, anemia and leukemia. ${ }^{2,3}$ 
Pharmacological activities of A. chica have been the subject of several puplications..$^{4-12}$ Recently, the Ministry of Health in Brazil expanded the number of medicinal plants of interest for use by the Unified Health System (Sistema Único de Saúde-SUS) in 2008. Among the approval of the seventy medicinal plants is $A$. chica, which requires its standardization. ${ }^{13}$

A. chica is easily cultivated and fast growing. In Amazonas State, the A. chica variety that predominates in the traditional use is known as variety I, according to the National Agricultural Research Corporation (Embrapa Amazonia Ocidental, Brazil). The leaves of this variety are thin and grow upwards, making A. chica suitable for cultivation in home gardens. Other varieties (designated as varieties II and III) have wider leaves with the tendency to grow horizontally (Figures S1 and S2 from Supplementary Information). The three varieties of $A$. chica have green coloration while fresh, but after drying they become brownish-red. The red nuance can be more evident if drying is performed under the sunlight. This happens due to the natural oxidation of components that are present in the plant. The use of the extract of the A. chica leaves was first reported by the Indians from regions of Colombia and Venezuela as a natural pigment known as "chica red". The pigment had high commercial value in former times. Nowadays, several cosmetic products containing A. chica (as crajiru) are registered in the National Health Surveillance Agency (Anvisa, Brazil) ${ }^{14}$ and commercialized by cosmetic industries, mainly in the Northern part of Brazil. These products exploit the natural red-brown color of the extracts of the A. chica leaves, as well as their antimicrobial and astringent properties.

A. chica possess high anthocyanidin content, in particular 3-deoxyanthocyanidins which are responsible for the red coloration of the leaf extracts.

These include 6,7,4'-trihydroxy-5-methoxyflavylium (1, carajurone), ${ }^{4,10} 6,7$-dihydroxy-5,4'-dimethoxyflavylium (2, carajurin), ${ }^{4,8,10} 6,7,3^{\prime}, 4^{\prime}$ '-tetrahydroxy-5-methoxyflavylium $(3)^{4,10}$ and 6,7,3'-trihydroxy-5,4'-dimethoxyflavylium ions $(4)^{4}$ (Table S1). To our knowledge, compounds 1-4 have only been isolated from A. chica, making them quite specific marker substances and useful for fingerprint characterization for this plant species.

Electrospray ionization mass spectrometry (ESI-MS) fingerprinting has been demonstrated to offer a very fast and versatile technique for the screening of polar mixtures of organic and inorganic compounds of plant origin. For example, this technique has been applied to the analyses of propolis, ${ }^{15}$ whisky, ${ }^{16}$ beer ${ }^{17}$ and essential oils, ${ }^{18}$ to differentiate levels of ripeness of fruits, as well as their post harvesting processes, ${ }^{19}$ and for quality control and adulteration of perfumes and vegetable oils. ${ }^{20-22}$ This technique employs little sample preparation, yields immediate compositional information on the most ESI ionizable compounds through direct infusion and allows the identification of characteristic marker compounds in extracts.

PLS-DA (partial least squares-discriminant analysis) is a multivariate method that is employed to classify samples in classes. This classification models the relationship between two matrices, one containing the instrumental answers and another containing the class affiliation for each sample. The algorithm decomposes the two matrices using a determined number of latent variables such that the maximum separation among classes is obtained. ${ }^{23,24}$

In this work, the leaf extracts of the three different varieties of A. chica, which are cultivated by Embrapa Amazonia Ocidental, were characterized using ESI-MS fingerprinting. ESI-MS data were collected during the rainy and dry seasons and at three different times throughout the day to investigate the compositional variation within these varieties..$^{25}$ The ESI-MS data were treated using PLS-DA to investigate whether ESI-MS would differentiate the three A. chica varieties. The aim of this work was therefore to develop ESI-MS coupled to PLS-DA as a simple yet reliable technique to distinguish these three Amazonian varieties of A. chica via the analysis of leaf extracts. Another purpose of this work was to investigate whether 3-deoxyanthocyanidins 1-4, which so far have been found only in A. chica, could be used to differentiate varieties I-III.

\section{Experimental}

\section{Plant material}

For this study, three varieties of $A$. chica were used. They are designated by the Amazon population as varieties I (ACI), II (ACII) and III (ACIII) (Figure S1 and Figure S2). They are continuously cultivated at Embrapa Amazonia Ocidental which is located in Manaus City, Amazonas State in the central Amazon region (Brazil). Voucher specimens were deposited by Dr. Francisco Célio Maia Chaves at the EAFM Herbarium from Amazonas Federal Institute of Education, Science and Technology (IFAM-CMZL) in Manaus City. These voucher specimens received the access numbers: EAFM2900 (variety I), EAFM 2901 (variety II) and EAFM 2902 (variety III). Specimens were identified by Prof. Dr. Valdely Ferreira Kinupp as Arrabidaea chica (Humb. \& Bonpl.) Verlot.

\section{Sample preparation and extraction}

A. chica leaves from the three varieties (ACI, ACII and ACIII) were collected during the rainy (R) and dry (D) 
seasons. These are the two main seasons in this part of the Amazon region, corresponding to the periods of December to May and June to November, respectively. They were also collected at three different periods of the day: early morning (M), midday (L) and late afternoon (A) (Table 1). After drying in an oven at $40{ }^{\circ} \mathrm{C}$ for $8 \mathrm{~h}$, the leaves were milled to a fine powder and sieved using a 40 mesh sieve.

Table 1. Analyzed samples, all samples were extracted and analyzed in triplicate, the first analyzed set received code ' $a$ ' at the end of the codification, second set received a ' $b$ ' and third set received a 'c', as AC1-R-Ma, AC1-R-Mb and AC1-R-Mc, respectively

\begin{tabular}{|c|c|c|c|}
\hline A. chica variety & Harvest season & Harvest time & Codification \\
\hline \multirow{6}{*}{ I } & \multirow{3}{*}{ rainy season } & early morning & AC1-R-M \\
\hline & & midday & AC1-R-L \\
\hline & & late afternoon & AC1-R-A \\
\hline & \multirow{3}{*}{ dry season } & early morning & AC1-D-M \\
\hline & & midday & AC1-D-L \\
\hline & & late afternoon & AC1-D-A \\
\hline \multirow{6}{*}{ II } & \multirow{3}{*}{ rainy season } & early morning & AC2-R-M \\
\hline & & midday & AC2-R-L \\
\hline & & late afternoon & $\mathrm{AC} 2-\mathrm{R}-\mathrm{A}$ \\
\hline & \multirow{3}{*}{ dry season } & early morning & AC2-D-M \\
\hline & & midday & AC2-D-L \\
\hline & & late afternoon & AC2-D-A \\
\hline \multirow{6}{*}{ III } & \multirow{3}{*}{ rainy season } & early morning & AC3-R-M \\
\hline & & midday & AC3-R-L \\
\hline & & late afternoon & AC3-R-A \\
\hline & \multirow{3}{*}{ dry season } & early morning & AC3-D-M \\
\hline & & midday & AC3-D-L \\
\hline & & late afternoon & AC3-D-A \\
\hline
\end{tabular}

A 7\% formic acid (Merck, Darmstadt, Germany) in deionized water and methanol (Tedia, Fairfield, OH, USA) (1:1) stock solution (200 mL) was prepared. Milled leaves (100 mg) of each of the samples (Table 1) were extracted with $1 \mathrm{~mL}$ of the above prepared solution in polypropylene microtubes (Eppendorf ${ }^{\circledR}$ ). Each tube was agitated in a Vortex mixer for $1 \mathrm{~min}$ and centrifuged for $1 \mathrm{~min}$. Sample solutions were prepared by diluting an aliquot of $5 \mu \mathrm{L}$ of the supernatant from each centrifuge tube in $0.5 \mathrm{~mL}$ of the formic acid/methanol/water solution. Sample solutions were analyzed by direct infusion into the mass spectrometer. The above extraction, dilution and analysis sequence were repeated (duplicate) for the 18 samples.

A Q-TOF mass spectrometer (Micromass, Manchester, UK) with an electrospray interface and running in the positive ion mode was used to perform ESI-MS and ESI-MS/MS analyses. The ion source unit was operated at a desolvation temperature of $80^{\circ} \mathrm{C}$, capillary voltage of $2.1 \mathrm{kV}$ and cone voltage of $40 \mathrm{eV}$. Samples were directly infused at a rate of

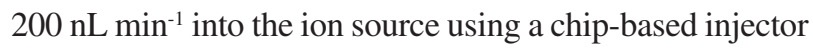
(Triversa NanoMate, Advion BioSciences, Norfolk, UK). The spectra were acquired in the interval of 150 to $1000 \mathrm{~m} / \mathrm{z}$ and accumulated for $60 \mathrm{~s}$. ESI-MS/MS were obtained for the deoxyanthocyanidin ions using collision energies ranging from 15 to $35 \mathrm{eV}$. The collision gas pressure (argon) was optimized to produce extensive fragmentation of the ions under investigation.

ESI-MS data were analyzed using the PLS-DA algorithm (PLS-Toolbox 4.02, Eigenvector Technologies, Manson, WA, USA). Ions with intensity below $20 \%$ relative to the most abundant ion were neglected during data treatment. All calculations and graphs were generated on a MatLab 6.5 platform (MathWorks, Natick, MA, USA).

\section{Results and Discussion}

Ions of $\mathrm{m} / \mathrm{z} 285,299,301$ and 315 corresponding to 3-deoxyanthocyanidins 1-4, respectively, are the major ions in positive mode ESI spectra in the three varieties of A. chica (Figure 1 and Table 2). The assignment of these ions to metabolites 1-4 was based on information from the literature ${ }^{4,10}$ and on the ESI(+)-MS/MS fragmentation analyses (Figure S3). These deoxyanthocyanidin ions exhibit as their main characteristics limited dissociation and analogous fragmentation patterns. The most prominent feature of this common fragmentation route is the primary loss of a methyl radical under higher collision energies and by occasional loss of CO. ${ }^{4,10}$

For a given variety of $A$. chica (I, II or III), little difference is perceivable in the mass spectra of extracts of the leaves that were harvested at three different times of day and in different seasons. Although all varieties display molecular cations of $m / z, 285,299$ and 301, these ions are sometimes of low intensity. For example, leaves of variety I exhibit a base ion of $\mathrm{m} / \mathrm{z} 299$ (50\% of the twelve spectra) or 463 (50\% of spectra), those of variety II always exhibit a base ion of $m / z$ 299, whereas those of variety III display the ion of m/z 301 as the most abudant. Considering that the $20 \%$ lowest relative abundance ions were neglected, the mass spectra of the three varieties differ in the relative abundances and proportions of these three molecular cations. The molecular cation of $\mathrm{m} / \mathrm{z} 315$ (which corresponds to 4) is only present in the ESI spectra of the leaves of variety III, independent of the season or time of day of sample collection. Therefore, the presence of this ion appears as a marker for variety III.

Analysis of the MS spectra of the three varieties of $A$. chica revealed that 101 signals remained after 


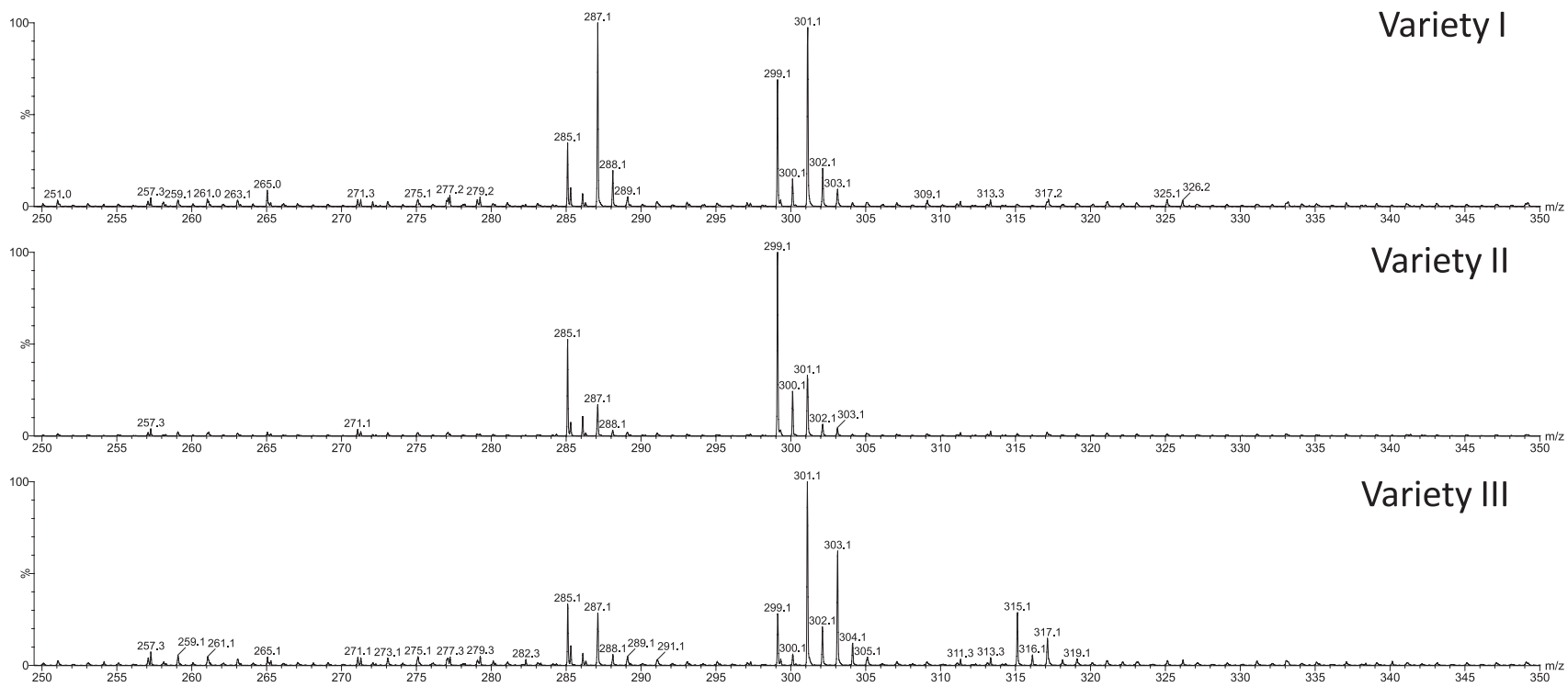

Figure 1. ESI(+)-MS of varieties a) I, b) II and c) III.

Table 2. Mass spectral signal intensity data for A. chica extracts harvested at different times of day and different seasons

\begin{tabular}{|c|c|c|c|c|c|c|c|c|c|}
\hline \multirow{3}{*}{$m / z$} & \multicolumn{9}{|c|}{ Relative mass spectral signal intensities } \\
\hline & \multicolumn{3}{|c|}{ Variety I } & \multicolumn{3}{|c|}{ Variety II } & \multicolumn{3}{|c|}{ Variety III } \\
\hline & Range & Avg & $\mathrm{SD}$ & Range & Avg & SD & Range & Avg & SD \\
\hline 158.1 & $0.0-12.8$ & 4.6 & 5.1 & 0.0 & 0.0 & 0.0 & 0.0 & 0.0 & 0.0 \\
\hline 160.1 & $0.0-13.2$ & 9.3 & 4.6 & $0.0-12.6$ & 8.9 & 3.3 & $10.3-18.7$ & 13.7 & 2.2 \\
\hline 164.1 & 0.0 & 0.0 & 0.0 & $0.0-6.4$ & 1.5 & 2.7 & $8.1-16.6$ & 11.2 & 2.2 \\
\hline 203.1 & $0.0-6.0$ & 0.5 & 1.7 & $0.0-7.3$ & 2.5 & 2.5 & $0.0-6.7$ & 2.8 & 2.6 \\
\hline 243.1 & $0.0-3.6$ & 0.3 & 1.0 & $0.0-5.0$ & 1.1 & 1.7 & $0.0-4.9$ & 0.9 & 1.6 \\
\hline 271.1 & $0.0-5.6$ & 1.5 & 2.2 & $0.0-4.5$ & 1.4 & 1.6 & $0.0-4.1$ & 0.8 & 1.6 \\
\hline 285.1 & $0.0-24.3$ & 11.1 & 9.0 & $12.6-20.2$ & 15.6 & 2.3 & $0.0-8.6$ & 5.8 & 2.1 \\
\hline 287.1 & $0.0-15.2$ & 9.0 & 6.7 & 0.0 & 0.0 & 0.0 & $0.0-20.5$ & 6.0 & 6.0 \\
\hline 299.1 & $4.8-38.6$ & 17.7 & 12.0 & $31.4-40.5$ & 35.2 & 2.6 & $0.0-11.0$ & 3.2 & 4.2 \\
\hline 301.1 & $0.0-14.4$ & 6.6 & 6.9 & 0.0 & 0.0 & 0.0 & $0.0-21.7$ & 15.0 & 6.1 \\
\hline 303.1 & $0.0-3.1$ & 0.8 & 1.2 & $0.0-2.8$ & 1.9 & 0.9 & $0.0-11.1$ & 2.9 & 4.5 \\
\hline 315.1 & 0.0 & 0.0 & 0.0 & 0.0 & 0.0 & 0.0 & $0.0-7.7$ & 5.0 & 2.0 \\
\hline 317.1 & $0.0-2.7$ & 0.8 & 1.2 & $0.0-2.2$ & 1.1 & 0.9 & $0.0-3.6$ & 0.6 & 1.4 \\
\hline 357.2 & $1.6-9.3$ & 5.7 & 2.8 & $0.0-3.8$ & 2.5 & 1.2 & 0.0 & 0.0 & 0.0 \\
\hline 357.3 & 0.0 & 0.0 & 0.0 & 0.0 & 0.0 & 0.0 & $0.0-4.4$ & 2.7 & 1.4 \\
\hline 365.1 & 0.0 & 0.0 & 0.0 & $0.0-1.0$ & 0.2 & 0.4 & $0.0-2.0$ & 1.1 & 0.8 \\
\hline 447.1 & $0.0-1.9$ & 0.6 & 0.8 & $0.0-1.5$ & 1.0 & 0.5 & $0.0-0.9$ & 0.1 & 0.3 \\
\hline 463.1 & $2.0-18.8$ & 10.7 & 6.3 & $1.0-12.5$ & 7.9 & 3.4 & $1.1-9.2$ & 6.7 & 2.8 \\
\hline 477.2 & $1.0-10.9$ & 6.1 & 3.8 & $0.7-7.4$ & 4.3 & 1.9 & $0.0-2.8$ & 2.0 & 0.8 \\
\hline 479.2 & 0.0 & 0.0 & 0.0 & 0.0 & 0.0 & 0.0 & $0.0-9.9$ & 6.6 & 3.3 \\
\hline 533.2 & $0.0-3.0$ & 1.0 & 1.4 & $0.0-1.5$ & 0.9 & 0.5 & $0.0-1.4$ & 0.9 & 0.4 \\
\hline 585.2 & $0.0-1.8$ & 0.6 & 0.7 & $1-5.5$ & 2.7 & 1.4 & $0.0-0.5$ & 0.1 & 0.2 \\
\hline 593.3 & $1.6-3.1$ & 2.2 & 0.5 & $0.9-5.6$ & 2.6 & 1.2 & $0.0-3.6$ & 1.5 & 1.4 \\
\hline 593.4 & 0.0 & 0.0 & 0.0 & 0.0 & 0.0 & 0.0 & $0.0-3.4$ & 1.1 & 1.4 \\
\hline 599.2 & $0.0-1.0$ & 0.2 & 0.4 & $0.8-3.6$ & 2.1 & 1.0 & $0.0-0.8$ & 0.2 & 0.3 \\
\hline
\end{tabular}

Avg and SD: average and standard deviation of mass spectral signal intensities, respectively; relative intensity data above are representative of each variety of A. chica independent of time of day and season of the collection; the data from the table were generated from Table S2 (Supplementary Information) excluding initial ions with intensity lower than $20 \%$ base peak intensity; remaining peak intensities were normalized and those ions having average relative intensities lower than $1 \%$ were also eliminated, with exception of ions corresponding to substances that were already isolated from A. chica $(\mathrm{m} / \mathrm{z}$. 285, 299,301 and 315 , in bold text). 
elimination of the $20 \%$ least intense signals (Table S2). Of these 101 signals, those having low average relative intensities were further eliminated yielding the group of ions that are presented in Table 2. These 101 ions and their relative intensities were then subjected to the PLS-DA analysis. Out of the 3-deoxyanthocyanidins, it is possible to discern from Table 2 the following patterns of
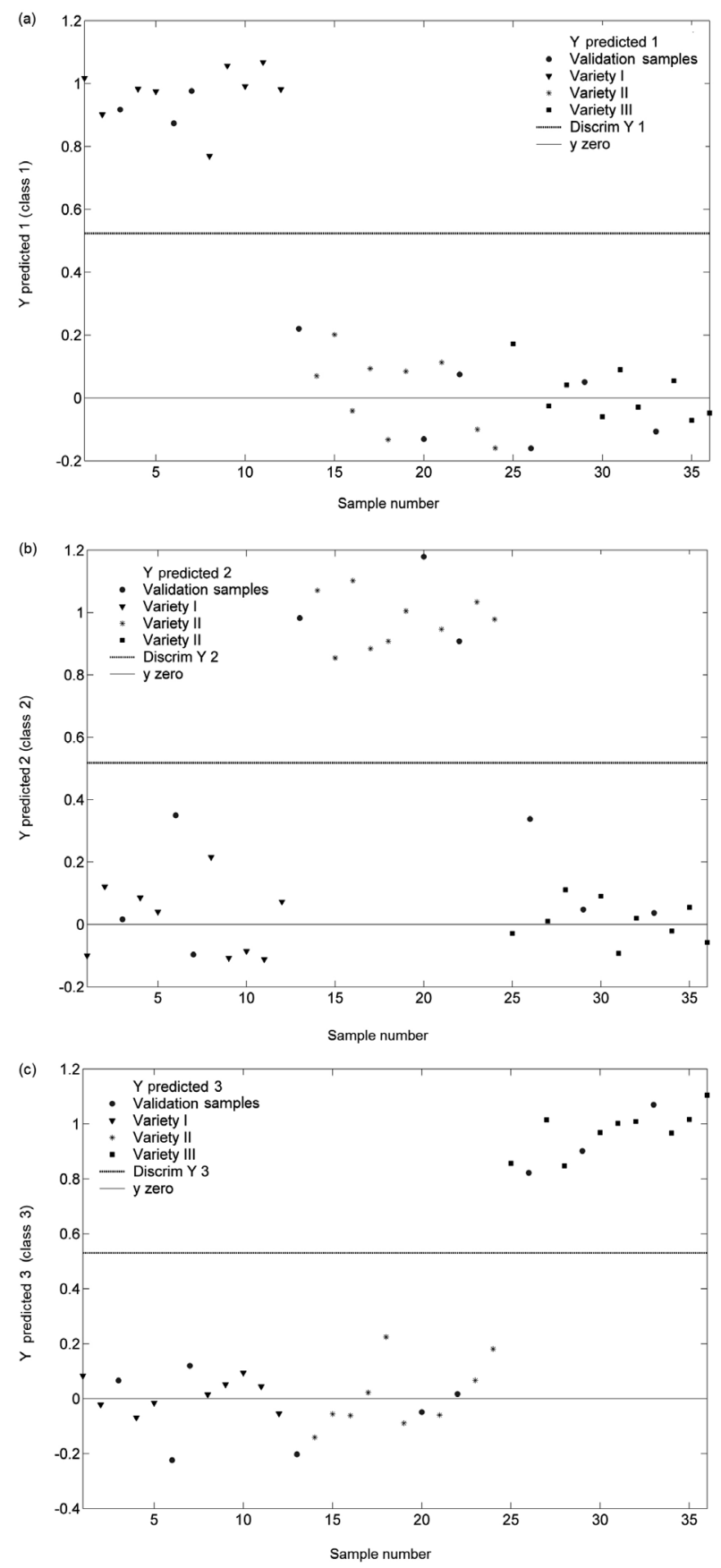

Figure 2. Plots generated using PLS-DA model and ESI(+)-MS data of the three varieties of A. chica: (a) samples from variety I falling in the line where $\mathrm{Y}$ is close to 1 , (b) samples from variety II falling in the line where $Y$ is close to 1 and (c) samples from variety III falling in the line where $\mathrm{Y}$ is close to 1 . relative intense ions $(\mathrm{m} / \mathrm{z}): 285,299$ and 301 for variety I, 285 and 299 for variety II and 285, 299, 301 and 315 for variety III. Average relative intensities lower than $1 \%$ were eliminated and are not in Table 2. The PLS-DA model was built in order to investigate whether the mass spectral data would differentiate and file the eighteen samples of the three varieties of $A$. chica in separate classes. The number of latent variables that were used in the models was chosen through cross-validation leave-one-out. The mass spectra were run in duplicate, and then organized so that samples 1-12 corresponded to variety I, samples 13-24 corresponded to variety II and samples 25-36 corresponded to variety III. Twenty-seven samples were selected for calibration, and three from each variety were used for validation: 3 , 6 and 7 from variety I, 13, 20 and 22 from variety II and 26, 29 and 33 from variety III. The algorithm was applied using six latent variables and the data set was mean centered. Three plots were generated (Figure 2) for each class/variety. In these plots, samples that fell above the dashed line (Discrim Y) belonged to a given class, whereas samples that fell below the dashed line did not belong to that particular class. All calibration and validation samples were correctly classified as varieties I, II and III, this can be seen in Figure 1. In Figure 2a-c, samples from variety I fall in values of $Y$ close to 1 , while samples from varieties II and III fall in the line of Y close to 0 .

According to the analyses of PLS-DA and other models, within a given variety of $A$. chica, there are no significant qualitative differences among the 3-deoxyanthocyanidin profiles from extracts corresponding to different harvest times and seasons (Table 1). This is an indication that variety is the most important aspect for defining the 3-deoxyanthocyanidin profile of A. chica.

\section{Conclusions}

ESI-MS data from leaf extracts that were treated by the PLS-DA model provide a simple and effective technique being able to classify the three varieties of $A$. chica. Seasonal and temporal effects seem not to affect the results.

\section{Supplementary Information}

Supplementary material (Figure S1-S3, Table S1-S2) is available free of charge at http://jbcs.sbq.org.br as PDF file.

\section{Acknowledgements}

Authors thank the Coordenação de Aperfeiçoamento de Pessoal de Nível Superior (CAPES) for scholarships and project support. 


\section{References}

1. Missouri Botanical Garden, http://www.tropicos.org accessed in June 2011.

2. Mors, W. B.; Rizzini, C. T.; Pereira, N. A.; DeFilipps R. A.; Medicinal Plants of Brazil; Reference Publications, Inc.: Algonac, MI, 2000, p. 501.

3. Duke, J.; Vasquez, R.; Amazonian Ethnobotanical Dictionary, $1^{\text {st }}$ ed.; CRC-Press: Boca Raton, FL, 1994, p. 215.

4. Zorn, B.; Garcia-Pineres, A.; Castro, V.; Murillo, R.; Mora, G.; Merfort, I.; Phytochemistry 2001, 56, 831.

5. Barata, L.; Schiozer, A.; Braga, A. M. P.; Schreiber, A. Z.; Lyra, L.; Br PI 0.600.943-3, 2006.

6. Barbosa, W. L. R.; Pinto, L. N.; Quignard, E.; Vieira, J. M. S; Silva Jr., J. O. C.; Albuquerque, S.; Bras. J. Pharmacogn. 2008, 18,544

7. Jorge, M. P.; Madjarof, C.; Ruiz, A. L. T. R.; Fernandes, A. T.; Sousa, I. M. O.; Foglio, M. A.; Carvalho, J. E.; J. Ethnopharmacol. 2008, 118, 361.

8. Chapman, E.; Perkin, A. G.; Robinson, R.; J. Chem. Soc. 1927, 3015.

9. Pauly, M.; Pauly-Florentiny, M.; Moser, P.; WO Patent 052809, 2001.

10. Devia, B.; Llabres, G.; Wouters, G.; Dupont, L.; Phytochem. Anal. 2002, 13, 114.

11. Schiozer, A. L.; Março, P. H.; Barata, L.E.S.; Poppi, R. J.; Anal. Lett. 2008, 41, 1592.

12. Barros, F. C. F.; Pohlit, A. M.; Chaves, F. C. M.; Rev. Bras. Plantas Med. 2008, 10, 38.

13. http://portal.saude.gov.br/portal/arquivos/pdf/RENISUS.pdf accessed in June 2010.

14. http://www7.anvisa.gov.br/datavisa/Notificado/notificado.asp accessed in June 2010.
15. Sawaya, A. C. H. F.; Tomazela, D. M.; Cunha, I. B. S.; Bankova, V. S.; Marcucci, M. C.; Custodio, A. R.; Eberlin, M. N.; Analyst 2004, 129, 739.

16. Moller, J. K. S.; Catharino, R. R.; Eberlin, M. N.; Analyst 2005 , 130,890

17. Araújo, A. S.; Rocha, L. L.; Tomazela, D. M.; Sawaya, A. C. H. F.; Almeida, R. R.; Catharino, R. R.; Eberlin, M. N.; Analyst 2005, 130, 884.

18. Moller, J. K. S.; Catharino, R. R.; Eberlin, M. N.; Food Chem. 2007, 100, 1283 .

19. Amorim, A. C. L.; Hovell, A. M. C.; Pinto, A. C.; Eberlin, M. N.; Arruda, N. P.; Pereira, E. J.; Bizzo, H. R.; Catharino, R. R.; Moraes Filho, Z. B.; Resende, C. M.; J. Braz. Chem. Soc. 2009, 20, 313 .

20. Marques, L. A.; Catharino, R. R.; Bruns, R. E.; Eberlin, M. N.; Rapid Commun. Mass Spectrom. 2006, 20, 3654.

21. Saraiva, S. A.; Cabral, E. C.; Eberlin, M. N.; Catharino, R. R.; J. Agric. Food Chem. 2009, 57, 4030.

22. Law, W. S.; Chen, H. W.; Balabin, R.; Berchtold, C.; Meier, L.; Zenobi, R.; Analyst 2010, 135, 773.

23. Ciosek, P.; Brzózka Z.; Wróblewski, W.; Martinelli, E.; Di Natale, C.; D’Amico, A.; Talanta 2005, 67, 590.

24. Barker, M.; Rayens, W.; J. Chemometr. 2003, 17, 166.

25. García-Plazaola, J. I.; Artetxe, U.; Becerril, J. M.; Plant Sci. 1999, 143, 125.

Submitted: April 3, 2011

Published online: January 10, 2012

FAPESP has sponsored the publication of this article. 